\title{
LAND COVER CLASSIFICATION PERFORMANCE OF MULTISPECTRAL RTK UAVS
}

\author{
U. G. Sefercik ${ }^{1, *}$, T. Kavzoglu ${ }^{1}$, I. Colkesen ${ }^{1}$, S. Adali ${ }^{1}$, S. Dinc ${ }^{1}$, M. Nazar ${ }^{1}$, M. Y. Ozturk ${ }^{1}$ \\ ${ }^{1}$ Dept. of Geomatics Engineering, Gebze Technical University, Kocaeli, Turkey - (sefercik, kavzoglu, icolkesen)@gtu.edu.tr
}

KEY WORDS: UAV, Multispectral Camera, RTK, SFM, Classification

\begin{abstract}
:
Unmanned air vehicle (UAV) became an alternative airborne remote sensing technique, due to providing very high resolution and low cost spatial data and short processing time. Particularly, optical UAVs are frequently utilized in various applications such as mapping, agriculture, and forestry. Especially for precise agriculture purposes, the UAVs were equipped with multispectral cameras which enables to classify land cover easily. In this study, the land cover classification potential of DJI Phantom IV Multispectral, one of the most preferred agricultural UAVs in the world, was investigated using spectral angle mapper, minimum distance and maximum likelihood pixel-based classification techniques and object-based classification. In the investigation, a part of Gebze Technical University (GTU) Northern Campus, includes a large variety of land cover classes, was selected as the study area. The UAV aerial photos were achieved from $70 \mathrm{~m}$ flight altitude and processed using structure from motion (SfM)-based image matching software Agisoft Metashape. The pixel-based and object-based land cover classification processes were completed with ENVI and eCognition software respectively. 16 independent land cover classes were classified and the results demonstrated that the accuracies are $73.46 \%$ in spectral angle mapper, $75.27 \%$ in minimum distance and $93.56 \%$ in maximum likelihood pixel-based classification techniques and $90.09 \%$ in nearest neighbour object-based classification.
\end{abstract}

\section{INTRODUCTION}

In the geomatics engineering discipline, the data is acquired by using space-borne or airborne remote sensing techniques and terrestrial surveys. Each method has pros and cons. In spaceborne imagery, satellites pass over a specific area on certain dates and thus instantaneous data cannot be obtained. In addition, a few hundred $\mathrm{km}$ orbital heights limit the spatial resolution. In traditional airborne techniques, repetitive flights are not preferred due to high costs (Cömert et al., 2012). On the other hand, collecting data with terrestrial surveys has disadvantages in terms of time, labor, and high cost for large application areas. Unmanned aerial vehicle (UAV) technology provides advantages compared to traditional methods. Rapid, low cost and very high resolution data acquisition abilities and the performance of final three dimensional (3D) products make the UAV technology very popular. UAV is defined as an aircraft that can be operated manually or automatically without a pilot (Can and Kahveci, 2017). As in most technological developments, UAVs were first used for military purposes, and later on, with the advancement in UAV technology, they gained an important place in civilian areas. Different sensor systems (optical, lidar systems, etc.), GNSS (Global Navigation Satellite Systems) receivers, and communication systems can be included in UAVs as the payload. Thanks to added components of UAVs, automatic flights can be performed with the prepared photogrammetric flight plans. By obtaining information about buildings, roads, water areas, residential areas, industrial zones, agricultural areas, and forests from UAV photos, studies such as change analysis, disaster management, urban planning, weather monitoring, agricultural applications can be carried out (Altunkaya and Yastıklı, 2011).

In distinguishing and classifying objects on images, values representing the reflection amount of the objects within the area they cover are represented by the pixels, which are defined as the smallest element that makes up the image. Multispectral sensors are useful in examining different reflection properties of the earth and objects. Thanks to multispectral data, which has a very important place in remote sensing applications, various analyses and observations can be made. For instance, monitoring crop growth in agricultural studies, determining soil properties, inspecting water pollution in hydrological studies, monitoring ship waste, volcanic research, and finding infected trees in forestry studies (Kavzoğlu and Çölkesen, 2011). Satellite platforms are generally considered the main source for obtaining multispectral imagery. But satellite imagery is generally insufficient regarding the temporal and spatial resolution, in projects that require high accuracy and precision. Providing multispectral imagery with high spatial and temporal accuracy instantaneously multispectral UAVs are quickly becoming popular (Doğan and Yıldız, 2019). Multispectral UAVs are utilized in several land cover classification studies including post-fire land cover analysis, coastal sand dune monitoring, detection of mining areas, classification of various vegetation areas (Choi et al., 2017; Al-Ali et al., 2020; Giang et al., 2020; Furukawa et al., 2021; Lazzeri et al., 2021).

In this study, using the data obtained from DJI Phantom IV Multispectral UAV, pixel-based and object-based land cover classification performance of multispectral UAVs were analyzed. In the analysis, spectral angle mapper (Girouard et al., 2004), minimum distance (Sisodia et al., 2014) and maximum likelihood (Ahmad and Quegan, 2012) pixel-based classification techniques and nearest neighbour object-based classification were applied on 16 independent land cover classes.

\section{STUDY AREA AND MATERIALS}

As the study area, a part of Gebze Technical University Northern Campus was chosen. The area is $500 \mathrm{~m} \times 225 \mathrm{~m}$ and contains different land cover classes such as farmland, buildings, trees and roads. Heights above sea level (orthometric) in the area varies between $4 \mathrm{~m}$ and $20 \mathrm{~m}$, and the topography is relatively flat. Figure 1 shows the Gebze Technical University Campus (red borders) and the selected study area on the Northern part of the Campus. 

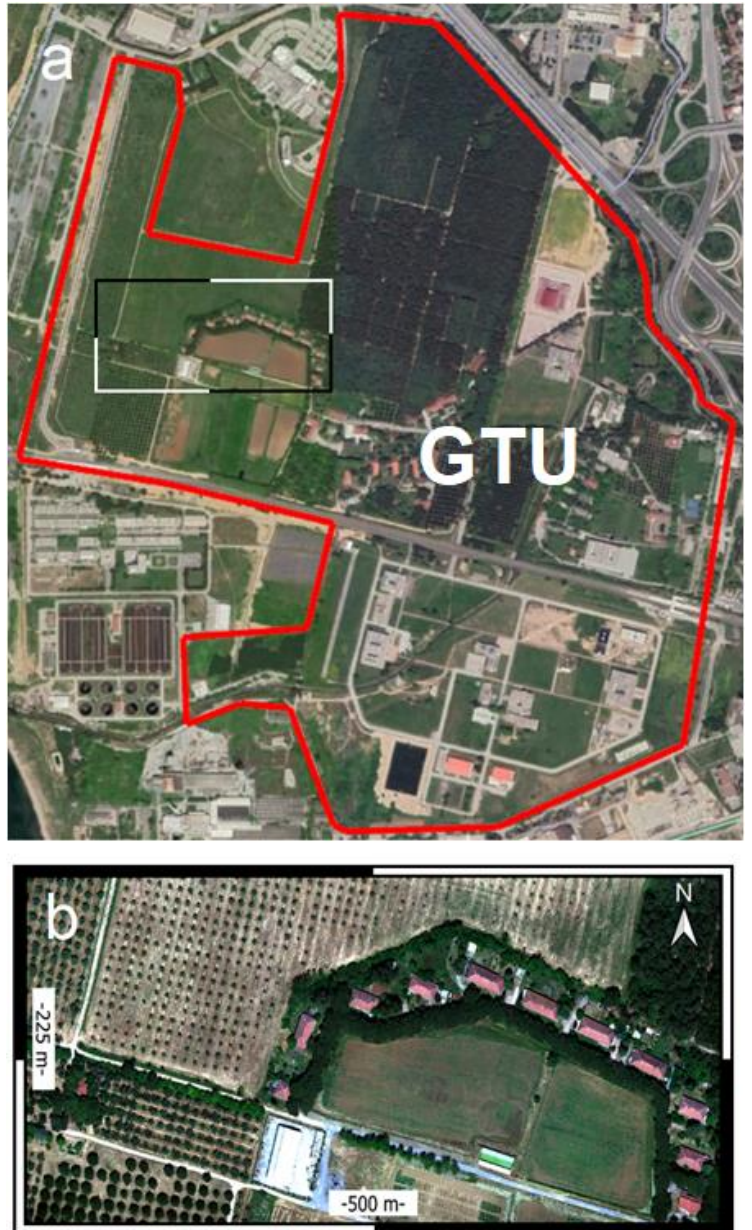

Figure 1. GTU Campus (a), Study area (b)

For the acquisition of multispectral aerial photos, real time kinematic (RTK) GNSS equipped DJI Phantom IV Multispectral UAV, available at GTU Geomatics Engineering Department's Advanced Remote Sensing Technology Laboratory, was used. The UAV has six imaging bands as RGB, red, green, blue, red edge and near infrared. For the reflectance calibration, MAPIR Camera Reflectance Calibration Ground Target Package (V2) was utilized. Figure 2 shows the UAV and reflectance calibration panel, used. Following Table 1 presents the specifications of the UAV.

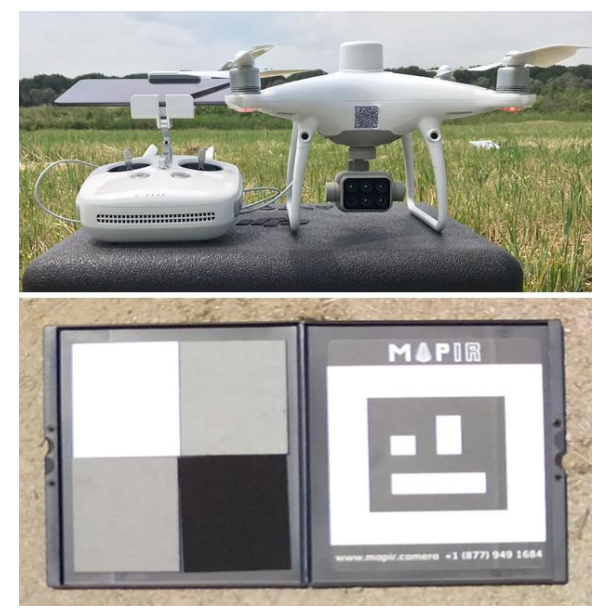

Figure 2. DJI Phantom IV Multispectral UAV and MAPIR Camera Reflectance Calibration Ground Target Package (V2)

\begin{tabular}{|c|c|}
\hline \multicolumn{2}{|c|}{ DJI Phantom IV Multispectral UAV } \\
\hline Camera & $\begin{array}{l}\text { Six } 1 / 2.9 " \text { CMOS sensors } \\
\text { including one RGB and five } \\
\text { monochrome, effective pixels } \\
2.08 \mathrm{MP}\end{array}$ \\
\hline Sensor wavelengths & $\begin{array}{l}\text { Blue (B): } 450 \mathrm{~nm} \pm 16 \mathrm{~nm} \text {; } \\
\text { Green }(\mathrm{G}): 560 \mathrm{~nm} \pm 16 \mathrm{~nm} \text {; Red } \\
(\mathrm{R}): 650 \mathrm{~nm} \pm 16 \mathrm{~nm} ; \\
\text { Red edge (RE): } 730 \mathrm{~nm} \pm 16 \mathrm{~nm} \text {; } \\
\text { Near-infrared (NIR): } 840 \mathrm{~nm} \pm \\
26 \mathrm{~nm}\end{array}$ \\
\hline Gimbal & 3-axis (pitch, roll, yaw) \\
\hline Flight duration & Max. 27 minutes \\
\hline Weight & $1487 \mathrm{~g}$ \\
\hline Speed & $14 \mathrm{~m} / \mathrm{s}(\mathrm{P}-\mathrm{mod}) ; 16 \mathrm{~m} / \mathrm{s}(\mathrm{A}-\mathrm{mod})$ \\
\hline Wind speed resistance & Max. $10 \mathrm{~m} / \mathrm{s}$ \\
\hline Operating temperature & $0^{\circ}$ to $40^{\circ} \mathrm{C}$ \\
\hline $\begin{array}{l}\text { Outdoor positioning } \\
\text { module }\end{array}$ & $\begin{array}{l}\text { GPS, GLONASS, Galileo, } \\
\text { Beidou }\end{array}$ \\
\hline Hover accuracy range & $\begin{array}{l}\text { RTK enabled: } \\
\pm 0.1 \mathrm{~m} \mathrm{~V}, \pm 0.1 \mathrm{~m} \mathrm{H} ; \\
\text { RTK disabled: } \\
\pm 0.1 \mathrm{~m} \mathrm{~V}, \pm 0.3 \mathrm{~m} \mathrm{H} \text { (Vision); } \\
\pm 0.5 \mathrm{~m} \mathrm{~V}, \pm 1.5 \mathrm{~m} \mathrm{H} \text { (GPS) } \\
\end{array}$ \\
\hline $\begin{array}{l}\text { Positioning accuracy } \\
\text { RTK }\end{array}$ & $\begin{array}{l}1 \mathrm{~cm}+1 \mathrm{ppm} \text { Horizontal } \\
1.5 \mathrm{~cm}+1 \mathrm{ppm} \text { Vertical }\end{array}$ \\
\hline
\end{tabular}

Table 1. Specifications of DJI Phantom IV Multispectral UAV

MAPIR Camera Reflectance Calibration Ground Target Package (V2) contains four colours as black, dark grey, light grey and white. Table 2 lists the used reflectance values of the spectral bands in four colours of the MAPIR panel separately.

\begin{tabular}{lcccc}
\hline \multicolumn{1}{c}{ Bands } & Black & Dark Gray & Light Gray & White \\
\hline Blue & 0.0201364 & 0.1825563 & 0.2479796 & 0.7919165 \\
\hline Green & 0.0196304 & 0.1937623 & 0.2630370 & 0.8664320 \\
\hline Red & 0.0193714 & 0.1985430 & 0.2629007 & 0.8719577 \\
\hline Red Edge & 0.0195625 & 0.2128809 & 0.2627409 & 0.8699902 \\
\hline NIR & 0.0214593 & 0.2283683 & 0.2754859 & 0.8625244 \\
\hline
\end{tabular}

Table 2. Reflectance values of the spectral bands

\section{METHODOLOGY}

The methodology of the study consists of three steps as UAV data acquisition, data processing and orthomosaic generation and land cover classification.

For the acquisition of UAV aerial photos, two polygonal flights were planned via DJI GS (Ground Station) PRO software. For both flights, $70 \mathrm{~m}$ altitude was chosen to achieve a ground sampling distance $(\mathrm{GSD})$ of $3.66 \mathrm{~cm}$. The front and side overlaps were determined as $80 \%$ and $\% 60$ respectively. According to the prepared flight plans, UAV was set to take a photo every two seconds, with a speed of approximately 4.9 $\mathrm{m} / \mathrm{s}$. Before the flights, the photos of the MAPIR reflectance panel were taken for spectral calibration and IMU (Inertial Measurement Unit) and compass calibrations were completed. With UAV flights, 530 aerial photos were achieved.

In Agisoft Metashape software, the acquired aerial photos were matched after camera optimization and a dense point cloud was generated. For the generation of the dense point cloud from aerial photos, Agisoft Metashape uses the structure from motion $(\mathrm{SfM})$ technique which works under the same basic principle as 
stereoscopic photogrammetry (Dereli et al., 2019; Sefercik et al., 2020). It uses overlapping photos from multiple viewpoints to reconstruct camera position and camera geometry. With this method, it is possible to construct spatial relationships between common feature points. After filtering the dense point cloud, orthomosaic was produced. The geometric accuracy of the orthomosaic was checked by point-based accuracy assessment using 9 ground control points (GCP). The calculated root mean square errors (RMSE) are $\pm 1.1 \mathrm{~cm}$ in $\mathrm{X}, \pm 2.7 \mathrm{~cm}$ in $\mathrm{Y}$ and \pm 5.7 $\mathrm{cm}$ in $\mathrm{Z}$.

The pixel-based and object-based land cover classifications were completed using ENVI and eCognition software respectively. For pixel-based classification, the supervised classification methods spectral angle mapper (SAM), minimum distance classifier (MDC), and maximum likelihood classification (MLC) were used. In the study area, a total of 16 classes were identified, including steppe, grass bush, metal roof, shade, olive, uncultivated land, meadow grass, broadleaf, needle leaf, building tile, building white, rough road, soil, cultivated land, concrete, and water. Before the classification, auxiliary vegetation indices were calculated and used as auxiliary data in the classification process. These indices are the Normalized Difference Vegetation Index (NDVI) and the Normalized Difference Red Edge Index (NDRE). NDVI as the $6^{\text {th }}$ band and the NDRE as the $7^{\text {th }}$ band were added to the 5-band orthomosaic image by layer stack process. Training and test data were collected in the study area for the classification process. While collecting training and test data, care was taken to collect approximately the same number and from different areas while comparing spectral signatures. In total, 85693 training and 247152 test data were collected. In Table 3, the number of training and test data, utilized in the classification process are given.

\begin{tabular}{llllll}
\hline Class & Train & Test & Class & Train & Test \\
\hline Steppe & 5097 & 15554 & $\begin{array}{l}\text { Needle } \\
\text { Leaf }\end{array}$ & 5280 & 15646 \\
\hline $\begin{array}{l}\text { Grass } \\
\text { Bush }\end{array}$ & 5506 & 15674 & Red Roof & 5201 & 15340 \\
\hline $\begin{array}{l}\text { Metal } \\
\text { Roof }\end{array}$ & 5172 & 15682 & $\begin{array}{l}\text { White } \\
\text { Roof }\end{array}$ & 5123 & 15389 \\
\hline Shadow & 5879 & 15838 & $\begin{array}{l}\text { Gravel } \\
\text { Road }\end{array}$ & 5495 & 15345 \\
\hline Olive & 5055 & 15334 & Soil & 5476 & 15400 \\
\hline $\begin{array}{l}\text { Uncultiv } \\
\text { ated } \\
\text { Land }\end{array}$ & 5427 & 15342 & $\begin{array}{l}\text { Cultivated } \\
\text { Area }\end{array}$ & 5666 & 15190 \\
\hline $\begin{array}{l}\text { Meadow } \\
\text { Grass }\end{array}$ & 5031 & 15811 & Concrete & 5115 & 15163 \\
\hline $\begin{array}{l}\text { Broad } \\
\text { Leaf }\end{array}$ & 5334 & 15425 & Water & 5836 & 15019 \\
\hline
\end{tabular}

Table 3. Number of training and test data, utilized in the classification process

\section{RESULTS}

Figure 3 shows the generated orthomosaic before and after spectral calibration.

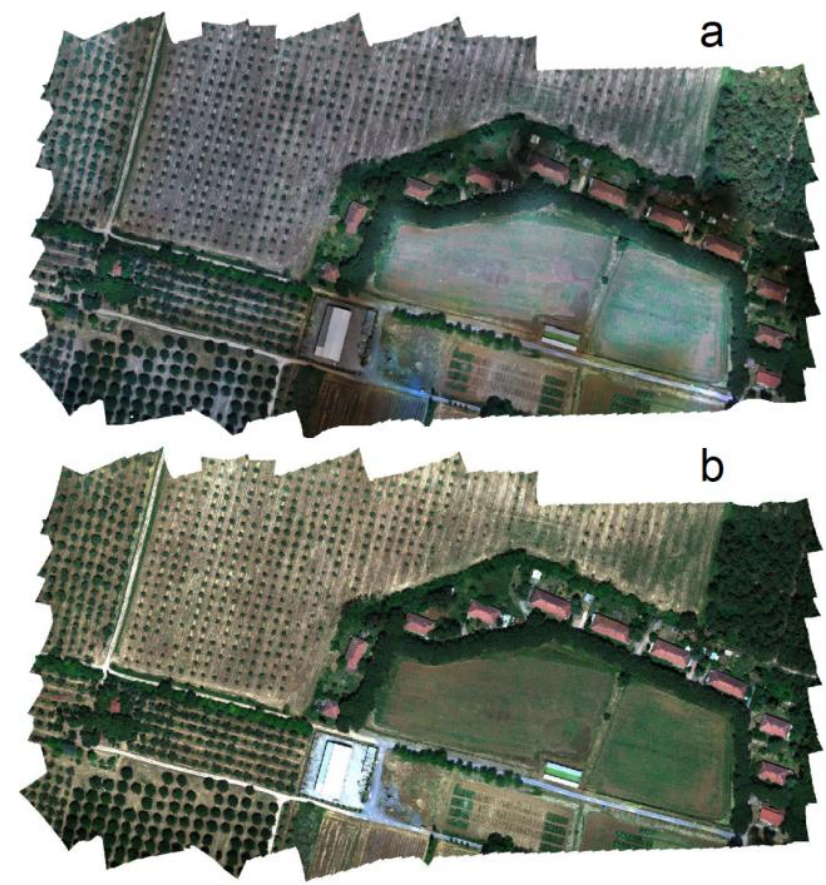

Figure 3. Generated orthomosaic: non-calibrated (a), calibrated (b)

Figure 4 shows the SAM, MDC and MLC pixel-based land cover classification maps. The accuracies of the classifications were achieved as $73.46 \%$ for SAM, $75.27 \%$ for MDC and $93.56 \%$ for MLC.
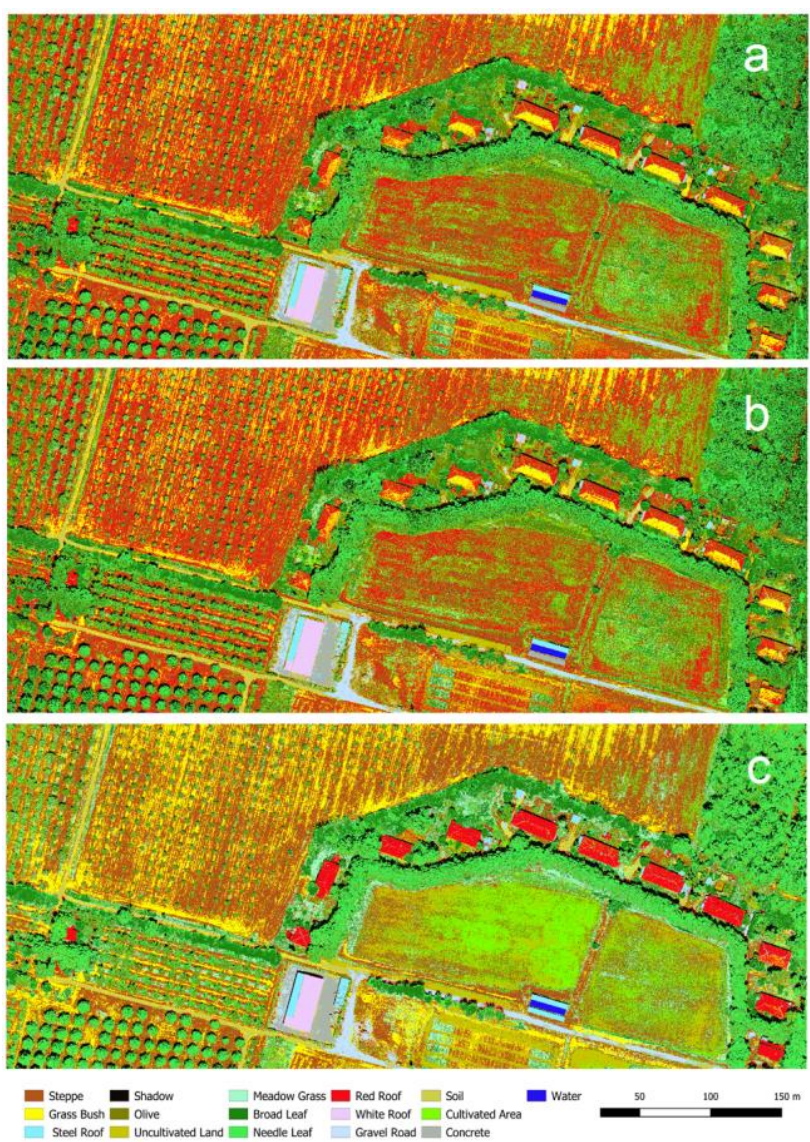

Figure 4. Classification maps of pixel-based techniques: SAM (a), MDC (b), MLC (c) 
Figure 5 displays the map of the nearest neighbour object-based classification result. The accuracy was achieved as $90.9 \%$.

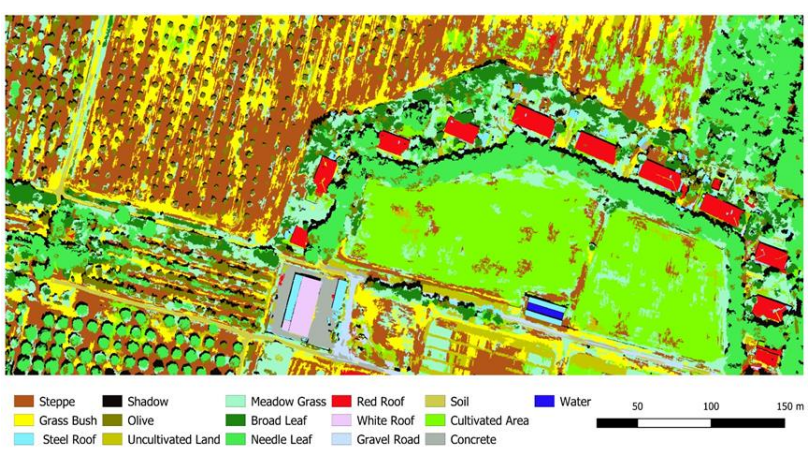

Figure 5. Nearest neighbour object-based classification map

The results demonstrated that the orthomosaic derived from DJI Phantom IV multispectral UAV has more than $90 \%$ accuracy both for pixel-based and object-based land cover classification. The classification map of MLC is much better than SAM and MDC.

\section{CONCLUSIONS}

In rapid rising UAV technology, thanks to the multispectral cameras, the spectral signatures of the objects are obtained sensitively and quickly. This study was organized to evaluate the land cover classification performance of multispectral UAVs. For this purpose, a study area that includes varied land cover classes in Gebze Technical University Northern Campus was preferred. With DJI Phantom IV Multispectral UAV flights, $3.66 \mathrm{~cm}$ GSD 6-bands aerial photos were achieved and calibrated orthomosaic was generated. SAM, MDC and MLC pixel-based land cover classification maps were produced from the orthomosaic and accuracy validations were performed. With 93.56\% accuracy, the MLC technique is much better than SAM and MDC. The visual structure and accuracy results of SAM and MDC are very close, $73.46 \%$ and $75.27 \%$ respectively. The accuracy of nearest neighbour object-based classification was determined as $90.9 \%$. Overall, the results demonstrated that the calibrated orthomosaic derived from DJI Phantom IV multispectral UAV has more than $90 \%$ accuracy both for pixelbased and object-based land cover classification.

\section{ACKNOWLEDGEMENTS}

We would like to thank TÜBİTAK for supporting this study within the scope of 2209-A University Students Research Projects Support Program.

\section{REFERENCES}

Ahmad, A., Quegan, S., 2012. Analysis of maximum likelihood classification on multispectral data. Applied Mathematical Sciences, 6(129), 6425-6436.

Al-Ali, Z. M., Abdullah, M. M., Asadalla, N. B., Gholoum, M., 2020. A comparative study of remote sensing classification methods for monitoring and assessing desert vegetation using a UAV-based multispectral sensor. Environmental Monitoring and Assessment, 192, 1-14. https://doi.org/10.1007/s10661-02008330-1

Altunkaya, Z., Yastıklı, N., 2011. Ortogörüntüler yardımıyla nesne tabanlı sınıflandırma yöntemi kullanılarak öznitelik çıarımı. In TMMOB Geographic Information Systems Congress, Antalya, Turkey.

Choi, S. K., Kim, G. H., Choi, J. W., Lee, S. K., Choi, D. Y., Jung, S. H., Chun, S. J., 2017. UAV-based land cover mapping technique for monitoring coastal sand dunes. Journal of the Korean Society of Surveying, Geodesy, Photogrammetry and Cartography, 35(1), 11-22. https://doi.org/10.7848/ksgpc.2017.35.1.11

Cömert, R., Avdan, U., Şenkal, E., 2012. İnsansız hava araçlarının kullanım alanları ve gelecekteki beklentiler. In 4th Remote Sensing and Geographic Information Systems Symposium, Zonguldak, Turkey.

Dereli, M. A., Polat, N., Uysal, M., 2019. Düşük maliyetli İHA ile yüksek çözünürlüklü SYM üretimi. Nevşehir Bilim ve Teknoloji Dergisi, 8(1), 56-62. https://doi.org/10.17100/nevbiltek.448558

Doğan, Y., Y1ldı, F., 2019. İHA ile multispektral kameralardan sağlanan görüntüler yardımıyla bitki türlerinin sınıflandırılması. Türkiye İnsansız Hava Araçları Dergisi, 1(1), 15-22.

Furukawa, F., Laneng, L. A., Ando, H., Yoshimura, N., Kaneko, M., Morimoto, J., 2021. Comparison of RGB and Multispectral Unmanned Aerial Vehicle for Monitoring Vegetation Coverage Changes on a Landslide Area. Drones, 5(3), 97. https://doi.org/10.3390/drones5030097

Giang, T. L., Dang, K. B., Le, Q. T., Nguyen, V. G., Tong, S. S., Pham, V. M., 2020. U-Net convolutional networks for mining land cover classification based on high-resolution UAV imagery. IEEE Access, 8, 186257-186273. https://doi.org/10.1109/ACCESS.2020.3030112

Girouard, G., Abdou, B., El Harti, A., Desrochers, A. 2004. Validated spectral angle mapper algorithm for geological mapping: comparative study between QuickBird and LandsatTM. Proc. XXth ISPRS Congress, Istanbul, Turkey.

Kavzoğlu, T., Çölkesen, İ., 2011. Uzaktan algılama teknolojileri ve uygulama alanları. In Sustainable Land Management Workshop in Turkey, 26-27.

Lazzeri, G., Frodella, W., Rossi, G., Moretti, S., 2021. Multitemporal Mapping of Post-Fire Land Cover Using Multiplatform PRISMA Hyperspectral and Sentinel-UAV Multispectral Data: Insights from Case Studies in Portugal and Italy. Sensors, 21(12), 3982. https://doi.org/10.3390/s21123982

Sefercik, U. G., Tanrikulu, F., Atalay, C., 2020. SFM Tabanlı Yeni Nesil Görüntü Eşleştirme Yazılımlarının Fotogrametrik 3B Modelleme Potansiyellerinin Karşılaştırması. Türkiye Fotogrametri Dergisi, 2(2), 39-45.

Sisodia, P. S., Tiwari, V., Kumar, A., 2014. A comparative analysis of remote sensing image classification techniques. International Conference on Advances in Computing, Communications and Informatics (ICACCI), 1418-1421. https://doi.org/10.1109/ICACCI.2014.6968245 